\title{
Hypoglycemia associated with L-asparaginase in acute lymphoblastic leukemia treatment: a case report
}

\author{
Ryuma Tanaka, Tomoo Osumi, Masashi Miharu, Tomohiro Ishii, Tomonobu Hasegawa, \\ Takao Takahashi and Hiroyuki Shimada*
}

\begin{abstract}
A patient with acute lymphoblastic leukemia repeatedly developed hypoglycemia during chemotherapy. Comparison of serum glucose trends between chemotherapy with and without L-asparaginase (L-Asp) demonstrated a strong association between L-Asp and hypoglycemia. Critical blood sampling during hypoglycemia indicated hyperinsulinism, suggesting that L-Asp induced hypoglycemia in the patient through inappropriate insulin secretion. Identification of hypoglycemia as an adverse effect will enable clinicians to understand and develop appropriate strategies for L-Asp use in chemotherapy regimens.
\end{abstract}

Keywords: L-asparaginase, Fasting hypoglycemia, Hyperinsulinism, Acute lymphoblastic leukemia, Fasting Glucose levels

\section{Background}

The enzyme L-asparaginase (L-Asp) has been commonly used for treatment of childhood acute lymphoblastic leukemia (ALL) for more than 30 years [1-3]. Because of its unique pharmacological features and historically improved treatment outcomes, L-Asp forms an essential part of ALL regimens worldwide [4]. However, many adverse effects of L-Asp have been documented, such as coagulopathy, acute pancreatitis, allergic reaction, hyperlipidemia, hyperammonemia, hepatotoxicity, and hyperglycemia [5-8]. Therefore, clinicians must carefully monitor patients treated with L-Asp for these adverse effects. Until date, hypoglycemia has not been formally reported as an adverse effect of L-Asp. We report, for the first time, a case of hypoglycemia associated with L-Asp use.

\section{Case presentation}

A 5-year-old girl with Philadelphia chromosome-positive ALL was treated with the induction therapy protocol of the Tokyo Children's Cancer Study Group (TCCSG)

\footnotetext{
* Correspondence: hshimada@a5.keio.jp

Department of Pediatrics, Keio University School of Medicine, 35

Shinanomachi, Shinjuku-ku, Tokyo 160-8582, Japan
}

L99-15 for high-risk patients. Therapy included prednisolone, vincristine, cyclophosphamide, daunorubicin, triple intrathecal injection, and L-Asp (Kyowa Hakko Kirin, Tokyo, Japan) [9]. The patient was administered $6000 \mathrm{IU} / \mathrm{m}^{2}$ of native Escherichia coli L-Asp on days $16,18,20,23,25,27,30,32$, and 34 of treatment. On day 18 , she developed fasting hypoglycemia (glucose, $56 \mathrm{mg} / \mathrm{dL}$ ) with severe hunger and without other signs or symptoms such as tremor, palpitation, anxiety, sweating, or paresthesias. On day 27 (fasting serum glucose level, $50 \mathrm{mg} / \mathrm{dL}$ ), critical blood sampling showed $6 \mathrm{U} / \mathrm{mL}$ of immunoreactive insulin, $0.47 \mathrm{mEq} / \mathrm{L}$ of free fatty acids, and $27 \mathrm{~mol} / \mathrm{L}$ of ketone bodies. She repeatedly developed fasting hypoglycemia (glucose, 38-65 mg/dL) until day 37, without serious complications (Figure 1). Five days after the last L-Asp administration, her fasting glucose levels were elevated from 73 to $87 \mathrm{mg} / \mathrm{dL}$. During induction therapy, fasting glucose levels were always measured before the morning steroid dose.

TCCSG L99-15 intensification-1, including high-dose cytarabine, methylprednisolone, L-Asp, and triple intrathecal injection, was started with daily imatinib. Thereafter, HR blocks of Berlin-Frankfurt-München (BFM) 2000 were administered. The HR blocks included cytarabine, 


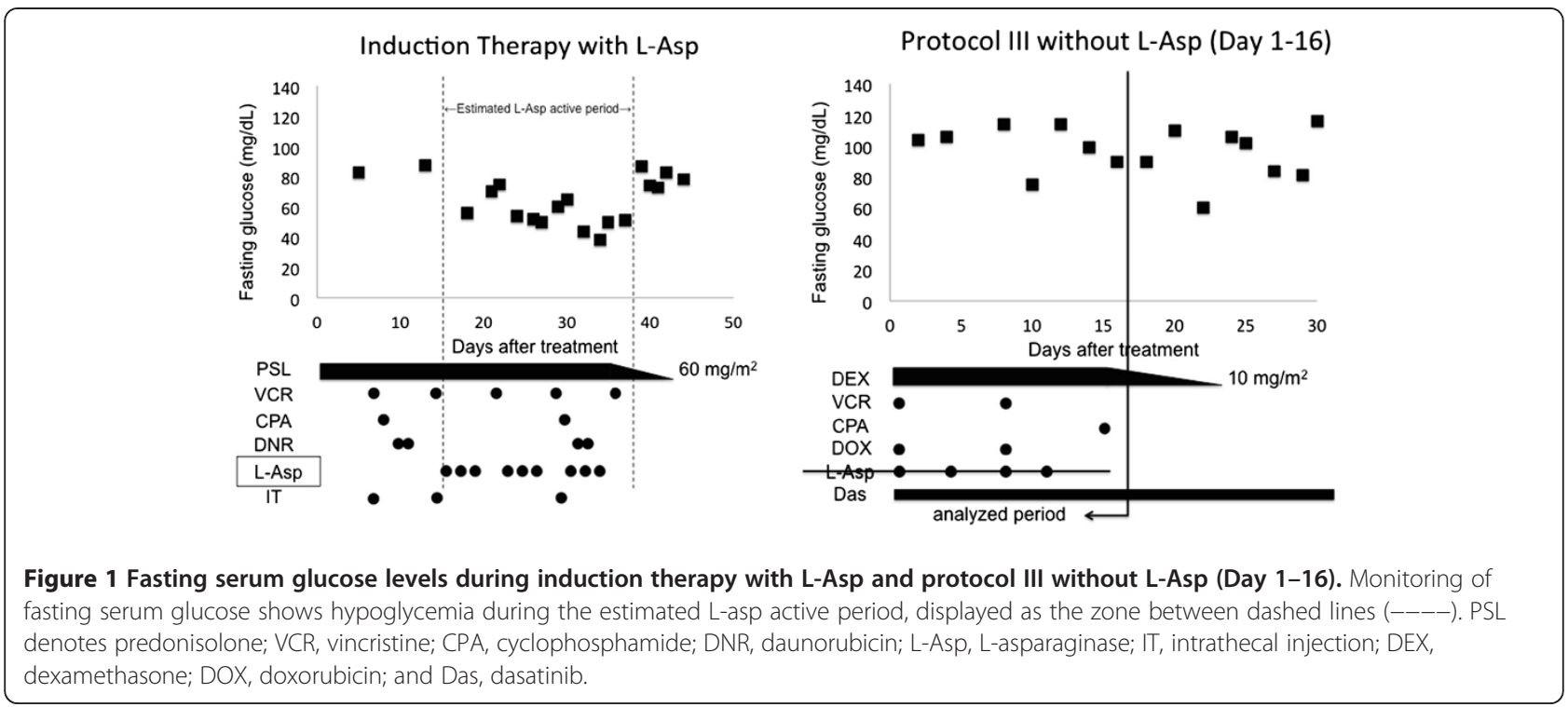

etoposide, methotrexate, vindesine, ifosfamide, daunorubicin, cyclophosphamide, dexamethasone, and L-Asp [10]. Daily dasatinib was included in the HR blocks instead of imatinib to avoid allergic reaction during TCCSG intensification-1. L-Asp was administered on day 5 of intensification-1 and days 6 and 11 of the HR block therapy. During early treatment days before L-Asp administration, the patient repeatedly developed fasting hyperglycemia (glucose, up to $132 \mathrm{mg} / \mathrm{dL}$ ). After L-Asp administration, she repeatedly experienced fasting hypoglycemia and was provided with supplemental food and intravenous fluid containing dextrose to prevent severe hypoglycemia.

At the end of the third HR block, she suffered acute pancreatitis. When chemotherapy was resumed after 2 weeks of treatment for pancreatitis, L-Asp was excluded from protocol III of BFM 2000 (reinduction therapy), which included dexamethasone, vincristine, doxorubicin, cyclophosphamide, cytarabine, mercaptopurine, and intrathecal methotrexate administration. During protocol III, the patient did not experience hypoglycemia and had relatively high fasting glucose levels, up to $114 \mathrm{mg} / \mathrm{dL}$ (Figure 1).

Glucose levels during the estimated L-Asp active period were significantly lower than those before and after the induction therapy period (Student $t$-test, $\mathrm{p}<0.05$ ). The estimated L-Asp active period was defined as that from the first administration to 4 days after the last administration during induction therapy, given that the patient's fibrinogen level decreased with L-Asp and spontaneously recovered 5 days after the last L-Asp administration. This estimation is supported by a report that L-Asp activity is retained for 3 days in the BFM 2000 protocol, where $5000 \mathrm{IU} / \mathrm{mL}$ L-Asp is administered at 3-day intervals [11].
Thereafter, a linear regression model was used to identify the relationship between fasting glucose levels, L-Asp, and glucocorticoid potency during induction therapy and protocol III, with the same treatment structure as that of induction therapy. Variables were entered into a leastsquares model. Prednisolone and dexamethasone potency was converted to hydrocortisone potency using 4:1 and 20:1 ratios, respectively [12]. Fasting glucose levels before and after the estimated L-Asp active period of induction therapy and during days $1-16$ of protocol III were treated as values without L-Asp, whereas fasting glucose levels during the estimated L-Asp active period were treated as values with L-Asp. Linear regression analysis showed that fasting glucose levels were significantly lower during the LAsp active period $(42.91 \mathrm{mg} / \mathrm{dL}, \mathrm{p}<0.001)$, and the hyperglycemic effect of glucocorticoids was significant (glucose, $0.084 \mathrm{mg} / \mathrm{dL}$ per $\mathrm{mg}$ hydrocortisone equivalence, $\mathrm{p}=0.015$ ), indicating the following equation: glucose $=0.084 \times$ [steroid potency $]-42.91 \times$ [L-Asp use (1 or 0$)]+78.96$ (Figure 2).

We confirmed that L-Asp activity was therapeutic during fasting hypoglycemia in the first HR block. L-Asp activity was $0.709 \mathrm{U} / \mathrm{mL}$ on day $10,0.674 \mathrm{U} / \mathrm{mL}$ on day 11 , and $1.78 \mathrm{U} / \mathrm{mL}$ on day 12 , where $25000 \mathrm{U} / \mathrm{m}^{2}$ of $\mathrm{L}$ Asp was administered on days 6 and 11. L-Asp activity was measured using the enzyme coupling methods described by Tsurusawa et al. [13,14]. L-Asp activity above $0.1 \mathrm{U} / \mathrm{mL}$ was generally considered therapeutic. The detection limit of this method was $0.002 \mathrm{U} / \mathrm{mL}$.

\section{Conclusions}

During ALL treatment, glucose levels are routinely monitored because many patients develop hyperglycemia, presumably because of glucocorticoids and L-Asp. Unexpectedly, our patient experienced repeated fasting 


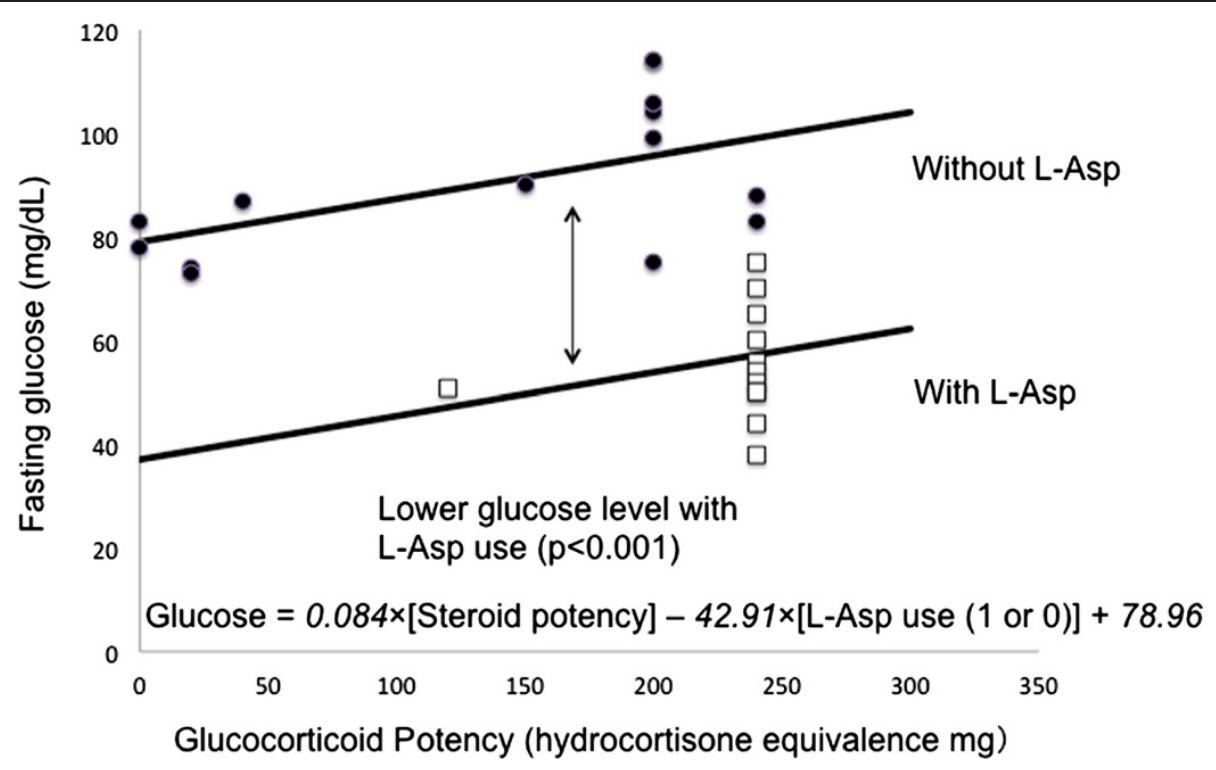

Figure 2 Linear regression analysis of fasting glucose, L-Asp, and glucocorticoid potency during induction therapy and protocol III. Linear regression analysis shows significant hypoglycemia during L-Asp use $(p<0.001)$ and a significant hyperglycemic effect of glucocorticoids $(p=0.015)$. Fasting glucose levels were plotted with L-Asp $(\square)$ and without L-Asp $(\bullet)$. Glucocorticoid potency is calculated as hydrocortisone equivalence with conversion ratios of 4:1 (prednisolone) and 20:1 (dexamethasone). L-Asp denotes L-asparaginase.

hypoglycemia during induction therapy, intensification-1, and HR block therapy. From induction through HR block therapy, L-Asp and steroids were both used and hypoglycemia was always observed after L-Asp use. Given the time relation between L-Asp administration and hypoglycemia, we hypothesized that our patient experienced L-Asp-induced hypoglycemia. Firstly, we compared fasting glucose levels with L-Asp and without L-Asp during induction (Student T-test), showing that those with L-Asp were significantly lower. After HR block therapy, L-Asp was excluded from protocol III because of the development of pancreatitis. Then, we compared fasting glucose levels during induction and first half of protocol III, the same backbone of treatment with and without L-Asp, respectively.

The following questions are to be answered: 1) How does L-Asp induce hypoglycemia? 2) Is there any use of other agents that might affect fasting glucose levels? 3) Why has hypoglycemia not been commonly seen or reported?

In response to the first question, inappropriate insulin secretion, normal free fatty acids, and low ketone bodies during severe hypoglycemia indicated hyperinsulinism, suggesting that L-Asp induced hypoglycemia through insulin hypersecretion. Regarding the second question, besides L-Asp use, there were the following differences between induction therapy and day 1-16 of protocol III; doxorubicin was used in protocol III instead of daunorubicin in induction therapy, and dasatinib was used in protocol III but not in induction therapy. Dasatinib has been not documented to cause the adverse effect of hyperglycemia or hypoglycemia. There was no use of other drugs that potentially induce hypoglycemia or hyperglycemia during these periods, such as non-steroidal antiinflammatory drugs, antibacterial agents, or imatinib [15]. To the third question, there are few reports focusing on fasting glucose levels in the morning [6,7]. Glucocorticoids are known to induce hyperglycemia through insulin resistance and gluconeogenesis during induction therapy for childhood ALL [16]. We suspect that parallel use of glucocorticoids may mask the hypoglycemic effect of L-Asp. Since different glucocorticoid agents were used in these two regimens, we treated glucocorticoids as an independent parameter with glucocorticoid potency conversion. Linear regression model showed a significant L-Asp hypoglycemic effect as well as glucocorticoid hyperglycemic effect. There was no significant interaction between L-Asp and glucocorticoids. There remains a concern with validity of glucocorticoid potency conversion for hyperglycemic effect. To overcome the limitation of this case report, further clinical data focusing on hypoglycemia are needed.

Use of L-Asp has recently become even more common in the adult ALL regimens [17]. We believe that in addition to the effect of L-Asp on leukemic cells, it is important to pay more attention to its pharmacological features and physiological mechanisms. Greater knowledge of these effects will enable clinicians to 
understand and develop appropriate strategies for L-Asp use in chemotherapy regimens.

\section{Consent}

Written informed consent was obtained from the patient's guardian for publication of this case report. A copy of the written consent is available for review by the Editor-in-Chief of this journal.

\section{Abbreviations}

L-Asp: L-asparaginase; ALL: Acute lymphoblastic leukemia; TCCSG: Tokyo Children's Cancer Study Group; BFM: Berlin-Frankfurt-München.

\section{Competing interests}

The authors declare that they have no competing interests.

\section{Authors' contributions}

RT designed and wrote the paper. TO, MM, and HS were responsible for the patient's overall treatment and review of the manuscript. TI and TH were responsible for the patient's endocrinological management and investigations. TT and HS performed their critical interpretation. All authors read and approved the final report.

\section{Acknowledgments}

We appreciate Mr. Haruki Honda for assisting in clinical data collection as a medical student.

Received: 18 March 2012 Accepted: 19 March 2012

Published: 19 April 2012

\section{References}

1. Möricke A, Zimmermann M, Reiter A, Henze G, Schrauder A, Gadner H, Ludwig WD, Ritter J, Harbott J, Mann G, Klingebiel T, Zintl F, Niemeyer C, Kremens B, Niggli F, Niethammer D, Welte K, Stanulla M, Odenwald E, Riehm $H$, Schrappe M: Long-term results of five consecutive trials in childhood acute lymphoblastic leukemia performed by the ALL-BFM study group from 1981 to 2000. Leukemia 2010, 24:265-284.

2. Tsuchida M, Ohara A, Manabe A, Kumagai M, Shimada H, Kikuchi A, Mori T, Saito M, Akiyama M, Fukushima T, Koike K, Shiobara M, Ogawa C, Kanazawa T, Noguchi Y, Oota S, Okimoto Y, Yabe H, Kajiwara M, Tomizawa D, Ko K, Sugita K, Kaneko T, Maeda M, Inukai T, Goto H, Takahashi H, Isoyama K, Hayashi Y, Hosoya R, Hanada R, Tokyo Children's Cancer Study Group: Long-term results of Tokyo Children's Cancer Study Group trials for childhood acute lymphoblastic leukemia, 1984-1999. Leukemia 2010, 24:383-396.

3. Gaynon PS, Angiolillo AL, Carroll WL, Nachman JB, Trigg ME, Sather HN, Hunger SP, Devidas M, Children's Oncology Group: Long-term results of the children's cancer group studies for childhood acute lymphoblastic leukemia 1983-2002: a Children's Oncology Group Report. Leukemia 2010, 24:285-297.

4. Pession A, Valsecchi MG, Masera G, Kamps WA, Magyarosy E, Rizzari C, van Wering ER, Lo Nigro L, van der Does A, Locatelli F, Basso G, Aricò M: Long-term results of a randomized trial on extended use of high dose L-asparaginase for standard risk childhood acute lymphoblastic leukemia. J Clin Oncol 2005, 23:7161-7167.

5. Raetz EA, Salzer WL: Tolerability and efficacy of L-asparaginase therapy in pediatric patients with acute lymphoblastic leukemia. J Pediatr Hematol Oncol 2010, 32:554-563.

6. Pui $\mathrm{CH}$, Burghen GA, Bowman WP, Aur RJ: Risk factors for hyperglycemia in children with leukemia receiving L-asparaginase and prednisone. J Pediatr 1981, 99:46-50.

7. Carpentieri U, Balch MT: Hyperglycemia associated with the therapeutic use of L-asparaginase: possible role of insulin receptors. J Pediatr 1978, 93:775-778.

8. Roberson JR, Raju S, Shelso J, Pui CH, Howard SC: Diabetic ketoacidosis during therapy for pediatric acute lymphoblastic leukemia. Pediatr Blood Cancer 2008, 50:1207-1212.

9. Manabe A, Ohara A, Hasegawa D, Koh K, Saito T, Kiyokawa N, Kikuchi A, Takahashi H, Ikuta K, Hayashi Y, Hanada R, Tsuchida M: Tokyo Children's
Cancer Study Group: Significance of the complete clearance of peripheral blasts after 7 days of prednisolone treatment in children with acute lymphoblastic leukemia: the Tokyo Children's Cancer Study Group Study L99-15. Haematologica 2008, 93:1155-1160.

10. Conter V, Bartram CR, Valsecchi MG, Schrauder A, Panzer-Grümayer R, Möricke A, Aricò M, Zimmermann M, Mann G, De Rossi G, Stanulla M, Locatelli F, Basso G, Niggli F, Barisone E, Henze G, Ludwig WD, Haas OA, Cazzaniga G, Koehler R, Silvestri D, Bradtke J, Parasole R, Beier R, van Dongen JJ, Biondi A, Schrappe M: Molecular response to treatment redefines all prognostic factors in children and adolescents with B-cell precursor acute lymphoblastic leukemia: results in 3184 patients of the AIEOP-BFM ALL 2000 study. Blood 2010, 115:3206-3214.

11. Schrey D, Borghorst S, Lanvers-Kaminsky C, Hempel G, Gerss J, Möricke A, Schrappe $M$, Boos J: Therapeutic drug monitoring of asparaginase in the ALL-BFM 2000 protocol between 2000 and 2007. Pediatr Blood Cancer 2010, 54:952-958.

12. Meikle AW, Tyler FH: Potency and duration of action of glucocorticoids. Effects of hydrocortisone, prednisone and dexamethasone on human pituitary-adrenal function. Am J Med 1977, 63:200-207.

13. Watanabe S, Miyake K, Ogawa C, Matsumoto H, Yoshida K, Hirabayashi S, Hasegawa D, Inoue T, Kizu J, Machida R, Ohara A, Hosoya R, Manabe A: The ex vivo production of ammonia predicts L-asparaginase biological activity in children with acute lymphoblastic leukemia. Int J Hematol 2009, 90:347-352.

14. Tsurusawa M, Chin M, Iwai A, Nomura K, Maeba H, Taga T, Higa T, Kuno T, Hori T, Muto A, Yamagata M: Japanese Children's Cancer and Leukemia Study Group: L-Asparagine depletion levels and L-asparaginase activity in plasma of children with acute lymphoblastic leukemia under asparaginase treatment. Cancer Chemother Pharmacol 2004, 53:204-208.

15. Ben Salem C, Fathallah N, Hmouda H, Bouraoui K: Drug-induced hypoglycemia: an update. Drug Saf 2011, 34:21-45.

16. Lowas SR, Marks D, Malempati S: Prevalence of transient hyperglycemia during induction chemotherapy for pediatric acute lymphoblastic leukemia. Pediatr Blood Cancer 2009, 52:814-818.

17. Hagop MK, Susan O, Terry LS, Cortes J, Giles FJ, Beran M, Pierce S, Huh Y, Andreeff M, Koller C, Ha CS, Keating MJ, Murphy S, Freireich EJ: Results of Treatment With Hyper-CVAD, a Dose-Intensive Regimen, in Adult Acute Lymphocytic Leukemia. J Clin Oncol 2000, 18:547-561.

doi:10.1186/2162-3619-1-8

Cite this article as: Tanaka et al.: Hypoglycemia associated with L-asparaginase in acute lymphoblastic leukemia treatment: a case report. Experimental Hematology \& Oncology 2012 1:8.

\section{Submit your next manuscript to BioMed Central and take full advantage of:}

- Convenient online submission

- Thorough peer review

- No space constraints or color figure charges

- Immediate publication on acceptance

- Inclusion in PubMed, CAS, Scopus and Google Scholar

- Research which is freely available for redistribution 